\title{
Concordance between practitioner questionnaire responses and observed clinical treatment recommendations for treatment of dentin hypersensitivity: findings from the National Dental Practice- Based Research Network
}

\author{
Mark S. Litaker ${ }^{1 *}$ D, Dorota T. Kopycka-Kedzierawski², D. Brad Rindal ${ }^{3}$, Jeffrey L. Fellows ${ }^{4}$, Marc W. Heft ${ }^{5}$,
}

Cyril Meyerowitz ${ }^{2}$, Sidney Chonowski ${ }^{6}$, Gregg H. Gilbert ${ }^{1}$ and The National Dental PBRN Collaborative Group

\begin{abstract}
Background: Few published reports have presented concordance between treatment choices selected by dentists in hypothetical clinical scenarios and treatment choices made by the same dentists in actual clinical practice. The aim of the current cross-sectional study, conducted within the Management of Dental Hypersensitivity (MDH) study, was to assess the potential value of practitioners' questionnaire responses regarding their typical treatment provided for management of dentin hypersensitivity $(\mathrm{DH})$, by evaluating agreement between these responses and subsequently-observed recommendations recorded during actual clinical examinations.

Methods: A total of 171 practitioners enrolled in the National Dental Practice-Based Research Network completed both a questionnaire and a clinical study regarding methods they use to treat dental hypersensitivity. The questionnaire solicited first-, second- and third-choice products when prescribing or recommending management of dentin hypersensitivity. Agreement was calculated for first-choice products/recommendations and for inclusion in the top three choices, as identified by the practitioners, from 11 listed treatment options. Overall percent agreement and Cohen's kappa statistic were calculated, with associated 95\% confidence intervals (CI). Associations between practitioner characteristics and agreement were also evaluated.

Results: For individual treatment modalities, percentage agreement ranged from 63 to 99\%, depending on the specific item. Percentage agreement between typical treatment and actual treatment for each practitioner's top three treatment modalities, as a combined grouping, ranged from 61 to 100\%. When these same agreement pairings were quantified to account for agreement above that expected by chance, kappa values were poor to low. (Continued on next page)
\end{abstract}

\footnotetext{
* Correspondence: mlitaker@uab.edu

'Department of Clinical and Community Sciences, University of Alabama at

Birmingham, 1919 7th Avenue South, Birmingham, AL 35294-0007, USA

Full list of author information is available at the end of the article
}

(c) The Author(s). 2019 Open Access This article is distributed under the terms of the Creative Commons Attribution 4.0 International License (http://creativecommons.org/licenses/by/4.0/), which permits unrestricted use, distribution, and reproduction in any medium, provided you give appropriate credit to the original author(s) and the source, provide a link to the Creative Commons license, and indicate if changes were made. The Creative Commons Public Domain Dedication waiver (http://creativecommons.org/publicdomain/zero/1.0/) applies to the data made available in this article, unless otherwise stated. 


\begin{abstract}
(Continued from previous page)
Conclusions: Concordance between hypothetical clinical scenarios and treatment choices made by the same dentists in actual clinical practice showed moderate to high levels of percentage agreement, but Cohen's kappa values suggested relatively low levels of agreement beyond that expected by chance. This analysis adds to the larger work of the network which has now observed a wide range of agreement between hypothetical and actual care, depending upon the specific diagnosis or treatment under consideration.

Questionnaire data for $\mathrm{DH}$ might serve as a useful adjunct to clinical data regarding treatment recommendations, but agreement was not sufficiently high to justify use of questionnaires alone to characterize patterns of treatment for this particular condition.
\end{abstract}

Keywords: Dentin hypersensitivity, National Dental Practice-Based Research Network, Agreement, Treatment modalities

\section{Background}

Previous studies have evaluated concordance between dentists' pre- and post-treatment observations in clinical practice [1], between dentists' questionnaire responses to hypothetical scenarios and responses collected during clinical treatments occurring subsequently [2,3], between different hypothetical scenarios [4], and between dentists' questionnaire responses and previously-published clinical standards of care $[5,6]$.

For example, one study calculated agreement between estimated depths of primary caries lesions, before and after operative treatment, for 8351 lesions in actual clinical practice. Unadjusted percentage agreement between dentists' pre- and post-operative depth assessments was $69 \%$ overall, $88 \%$ for lesions that were into the inner one-third of dentin and $52 \%$ for lesions in the outer one-half of enamel [1].

Other studies have reported concordance based on questionnaires or hypothetical scenarios alone, with no direct observation of clinical practice [4-7]. Few published reports have presented concordance between treatment choices selected by dentists in hypothetical clinical scenarios and treatment choices made by the same dentists in actual clinical practice. Heaven, et al., evaluated the association between dentists' decision to repair or to replace existing restorations in three hypothetical scenarios with treatment provided to patients in comparable clinical circumstances [3]. Percent agreement was not estimated, but dentists who recommended repair rather than replacement in more of the hypothetical scenarios did indeed have higher rates of repair in clinical practice. In a different study, pre-treatment estimates of lesion depths at which dentists placed initial restorations during a clinical study were compared with lesion depths at which they stated that they would place restorations in hypothetical scenarios [2]. The primary interest was in estimating the percentage of restorations for which the actual caries depths were less than the threshold depths indicated in the hypothetical scenarios.

The current analysis was conducted as a part of a National Dental Practice-Based Research Network study, the Management of Dentin Hypersensitivity (MDH)
Study. The objective of the MDH study was to evaluate the methods used by dentists to diagnose and treat dentin hypersensitivity (DH) $[8,9]$. The National Dental Practice-Based Research Network (the Network) is a consortium of dental practices and dental organizations focused on improving the scientific basis for clinical decision-making and moving evidence into everyday clinical practice. The structure and function of the Network have been published previously [10], and detailed information about the network is available online [11].

The objective of the current analysis was to evaluate concordance between stated preferences in treatment recommendations for $\mathrm{DH}$, based on practitioners' responses to a pre-study questionnaire, with observed recommendations made by the same practitioners during subsequent actual clinical treatment of their patients who were enrolled in the MDH study, which served as the parent study for this analysis. The purpose of evaluating concordance was to aid in assessing the value of practitioners' responses to questions regarding their typical practice methods, as these might be more easily obtained than observations based on actual patient visits.

\section{Methods \\ The MDH study}

Any general dentist or specialist who was enrolled in the Network at the full participation level was eligible to enroll in the study. Study practitioners completed all necessary human participant and conflict-of-interest training as required by the network.

Detailed procedures and inclusion and exclusion criteria for the MDH study have been previously reported $[8,9]$. Briefly, the study was reviewed and approved by the institutional review board of the home institution of the lead investigator (D.K.K.), as well as by those for each of the 6 administrative regions within the network. After enrolling in the study, practitioners completed an online questionnaire before enrolling patients. The results of the pre-study questionnaire have been previously published [8].

The practitioners recruited dental patients from their respective practices who reported having sensitive teeth 
and subsequently received a diagnosis of DH. Each patient provided informed consent to participate in the study. Patient inclusion criteria included that the patient was willing to be available for the duration of the study; was 19 years old or older; reported having a sensitive tooth or teeth with a diagnosis of DH (third molars were excluded), and that the patient granted permission for follow-up $[8,9]$. The exclusion criteria for patients were having a medical condition that could interfere with reliable pain reporting, having a chronic pain condition, having odontogenic pain, or reported having taken analgesics more than 3 times in the past week.

At the baseline visit, the practitioners completed the patient's oral examination, confirmed the diagnosis of $\mathrm{DH}$, completed a dental history form, and recommended, prescribed, or applied treatment for DH. Patients completed pain assessment forms at the baseline visit and at 1-, 4-, and 8-weeks post-visit. Sample size considerations were based on precision of estimation of percentages, adjusted for the effect of clustered sampling due to enrollment of multiple patients per dental practice. On the basis of this analysis, the target sample size of the study was set at approximately 180 practitioners and 1900 patients.

\section{The agreement study}

The current study is a cross-sectional analysis of agreement between: (1) practitioners' characterization of their typical treatments for $\mathrm{DH}$ as specified on the $\mathrm{MDH}$ study pre-study questionnaire; and (2) summary rates of treatment selections made during the baseline examination visit, calculated from each practitioner's sample of patients enrolled in the MDH study.

\section{Practitioner and practice data: the enrollment questionnaire}

Practitioners completed a Network enrollment questionnaire that collected information about themselves and their practices. The questionnaire is publicly available online [12]. Selected practitioner and practice characteristics were used to explore potential associations with agreement between predicted (typical) and observed treatment recommendations.

\section{Treatment recommendations, predicted: the practitioner questionnaire}

The initial stage of practitioner participation in the MDH study comprised completing an online questionnaire regarding methods used to diagnose and manage or treat $\mathrm{DH}$, as well as the practitioner's judgment regarding factors that predispose a patient to DH. The network's applicable Institutional Review Boards approved the study. All participants provided informed consent after receiving a full explanation of the procedures.

Development and testing of the questionnaire have been previously reported [8]. Briefly, the questionnaire was pilot tested using six dental practitioners who evaluated the length, acceptability and internet browser compatibility. Following revision based on this initial review, test-retest reliability of the questionnaire was evaluated for 24 additional practitioners [8].

Respondents were asked to select all procedures they routinely use to manage $\mathrm{DH}$ from the following list: (1) Fluoride products (includes gels, varnishes pastes and rinses), (2) Desensitizing OTC potassium nitrate toothpastes, (3) Glutaraldehyde/HEMA products, (4) Bonding agents, (5) Sealants, (6) Restorative treatments, (7) Lasers, (8) Oxalates, (9) No treatment, (10) Advice, and (11) Other. These are termed "treatment modalities" on the questionnaire. "No treatment" principally included dentists' advice and counseling regarding modifying toothbrushing rigor and type of toothbrushes or toothpaste type, reduction in the ingestion of acidic foods and drinks or discontinuing the use of tooth-whitening products.

Following the selection of individual treatments, the practitioners were asked to rank their first, second and third choices of the items they had selected. Results of the questionnaire have been previously reported [8]; the questionnaire is publicly available online [13].

\section{Treatment recommendations, observed: the patient examination form}

On patient examination forms, practitioners selected "treatment recommended and/or prescribed" from a provided list and were instructed to check all applicable items. The list items were the same as those on the Questionnaire, except that there were separate items for five fluoride products. For analysis, these were collapsed into a single "fluoride products" category in order to correspond to the single questionnaire item for these products.

For each dentist, frequencies were tabulated for each treatment recommendation. Percentages of the dentists' total recommendations were calculated for each recommendation. These percentages were ranked for each dentist to identify the most common and the top three recommendations. If two treatment recommendations were tied for most frequently used, then both of these were coded as the first choice for that dentist. These would be evaluated separately as agreement or disagreement with the questionnaire responses.

The patient examination form is publicly available online [14]. The practitioner questionnaire, baseline patient examination form and STROBE checklist for the Agreement Study are included as Additional files 1, 2 and 3.

\section{Statistical analysis}

Data analysis was conducted using $\mathrm{SAS}^{\circ}$ Release 9.4 software.

Frequencies of each product/treatment recommendation were tabulated for the patients who were examined by each practitioner, and these were ranked to identify 
the practitioner's first, second and third most frequently recommended treatment modalities. Dichotomous variables were coded to identify whether each item was the first-choice treatment recommendation and whether each item occurred among the top three most-used recommendations for each dentist.

Agreement was calculated between (1) dentists' typical product/treatment recommendations (based on the pre-study questionnaire) with (2) the observed rankings based on these same dentists' actual treatment recommendation (as recorded during their patient examinations). Agreement was evaluated separately for each listed product/recommendation, for the product/recommendation indicated as the dentist's first-choice and for products/ recommendations indicated as within the dentist's top three recommendations. Unadjusted percentage of agreement was used to characterize concordance between survey (typical) and (actual) clinical usage. Cohen's kappa statistic was used to evaluate agreement beyond that expected by chance. Point estimates and $95 \%$ confidence intervals were calculated for each measure.

Secondary analyses were conducted to evaluate practitioner and practice characteristics as potential predictors of agreement on the top three treatment recommendations. The outcome variables for these analyses were variables representing agreement between survey responses and clinical use for each treatment recommendation occurring among the three most common choices. The practitioner/practice characteristics that were evaluated as potential predictors were practitioner gender, race (categorized as white versus other due to small observed numbers of non-white respondents), age group (27-39, 40-49, 50-59, 60-73), full-time versus part-time, practice location (Inner city of urban area; Urban, not inner city; Suburban; Rural), and number of practice locations. Associations between practitioner/practice characteristics and agreement were evaluated using the chi-square statistic, separately for each treatment recommendation. No adjustment for multiple analyses was used.

\section{Results}

\section{Practices/practitioners and patients}

A total of 185 dentists from all six network regions completed the practitioner questionnaire. Of these, $171 \mathrm{com}$ pleted patient clinical examination forms for a total of 1862 patients and were included in the current study. Characteristics of the practitioners and patients have been previously reported $[8,9]$. Patient ages ranged from 19 to 87 (median $=45$ ).

The median number of patients enrolled per practitioner was 12 , with enrollment ranging from 1 to 16 patients. Six practitioners $(3.5 \%)$ enrolled a single patient each, and 21 practitioners $(12.3 \%)$ enrolled three or fewer. Sixty six practitioners (38.6\%) enrolled 16 patients each.
Regional distribution of the practitioners was relatively uniform, with $16.4-17.0 \%$ of the total from each of the Midwest, Southwest, South Central and South Atlantic regions. $14.6 \%$ were from the Western region and $18.1 \%$ were from the Northeast region.

\section{Agreement of survey responses with clinical recommendations} Percent agreement and Cohen's kappa statistic, representing agreement beyond that expected by chance, are presented in Table 1 for first-choice treatment recommendations. Desensitizing OTC potassium nitrate toothpaste was the product that was most often selected by the dentists as their first choice recommendation, with 84 dentists (49.1\%) choosing this item. Of these, 49 dentists $(58.3 \%)$ also indicated this recommendation most often in the clinical examinations. Overall agreement on this recommendation was $63.7 \%$ (95\% CI: 56.1, 70.9), with kappa $=0.27$ (95\% CI: 0.13, 0.42).

Fluoride products were selected on the questionnaire by 62 dentists $(36.3 \%)$ as their first choice. Among these, $33(53.2 \%)$ indicated fluoride products most often in the clinical examinations. Overall agreement for the recommendation of fluoride products was $63.2 \%$ (95\% CI: 55.5 , 70.4) and kappa $=0.22$ (95\% CI: 0.07, 0.37).

The other recommendation options were selected as their first choice by 0 to 6 dentists (0 to 3.5\%), which yielded relatively high percent agreement with observed rates for non-selection of these options. The lower $95 \%$ confidence limit for kappa includes zero for all but one recommendation, indicating no agreement beyond what would be expected by chance alone. The single exception was for use of lasers, which showed kappa $=1.0$ (95\% CI: 1.0, 1.0), based on only one dentist selecting this as the first-choice recommendation on the questionnaire. For this single dentist, laser treatment was also the most-used recommendation in the clinical data. There was complete agreement between the questionnaire and clinical observation for all other dentists regarding lasers not being their first choice of treatment. No dentists selected sealants as the first-choice product/recommendation, although for a single dentist this was the most commonly-indicated recommendation in the patient examinations.

Estimates of agreement with clinical recommendations for dentists' indication of products/recommendations as being first, second or third choice options are shown in Table 2. Overall agreement was somewhat higher for indication of products/recommendations among the top three options. Fluoride products were selected on the questionnaire by 156 dentists (91.2\%). Overall agreement with clinical recommendation of this product was $72.5 \%$ (95\% CI: $65.2,79.1)$, but kappa was only $0.08(-0.06,0.22)$, indicating that agreement did not exceed that expected by chance.

Desensitizing OTC potassium nitrate toothpaste was selected by 150 dentists (87.7\%), and overall agreement 
Table 1 Agreement on first-choice treatment recommendation for management of dentin hypersensitivity

\begin{tabular}{llll}
\hline Treatment Recommended & $\begin{array}{l}\text { Product Listed as First Choice on Survey } \\
\mathrm{n}(\%)\end{array}$ & $\begin{array}{l}\text { Agreement Between Survey and Exam } \\
\%(95 \% \mathrm{Cl})\end{array}$ & $\begin{array}{l}\text { Kappa } \\
(95 \% \mathrm{Cl})\end{array}$ \\
\hline $\begin{array}{l}\text { Desensitizing OTC Potassium } \\
\text { Nitrate Toothpaste }\end{array}$ & $84(49.1 \%)$ & $63.7 \%(56.1,70.9)$ & $0.27(0.13,0.42)$ \\
Fluoride Products & $62(36.3 \%)$ & $63.2 \%(55.5,70.4)$ & $0.22(0.07,0.37)$ \\
Glutaraldehyde/HEMA Products & $6(3.5 \%)$ & $95.9 \%(91.8,98.3)$ & $0.20(-0.16,0.57)$ \\
Advice & $6(3.5 \%)$ & $93.0 \%(88.1,96.3)$ & $-0.04(-0.06,-0.02)$ \\
Other & $6(3.5 \%)$ & $88.9 \%(83.2,93.2)$ & $0.13(-0.08, .034)$ \\
Restorative Treatments & $2(1.2 \%)$ & $97.1 \%(93.3,99.0)$ & $0.27(-0.17,0.71)$ \\
No Treatment & $2(1.2 \%)$ & $96.5 \%(92.5,98.7)$ & $-0.02(-0.03,-0.003)$ \\
Bonding Agents & $1(0.6 \%)$ & $95.9 \%(91.8,98.3)$ & $-0.01(-0.03,0.01)$ \\
Lasers & $1(0.6 \%)$ & $99.4 \%(96.8,100.0)$ & $1.0(1.0,1.0)$ \\
Oxalates & $1(0.6 \%)$ & $97.1 \%(93.3,99.0)$ & $-0.01(-0.02,0.01)$ \\
Sealants & $0(0 \%)$ & $99.4 \%(96.8,100.0)$ & ---
\end{tabular}

with clinical recommendations was 73.1\% (95\% CI: 65.8, 79.6), kappa $=0.26$ (95\% CI: 0.12, 0.41).

Glutaraldehyde/HEMA products, bonding agents, restorative treatments, and advice were indicated as top-three choices for at least $15 \%$ of dentists, and showed overall agreement ranging from 60.8\% (95\% CI: 53.1 , 68.2; kappa $=0.0$ ) for advice to $81.3 \%$ (95\% CI: 74.6, 86.8; kappa $=0.29$ ) for bonding agents. Fewer than $10 \%$ of dentists selected any of the other options as among their first-, second- or third choices.

\section{Practitioner/practice characteristics and agreement}

Only two practitioner characteristics showed statistically significant associations with agreement. Agreement on the recommendation of OTC potassium nitrate toothpaste differed by number of practice locations, with $76.2 \%$ agreement for practices having a single location, and 54.6\% for practices with multiple locations $(p=0.0322)$. Agreement on the selection of advice among the top three recommendations differed by type of practice location. Inner city, urban (not inner city) suburban and rural locations showed $53.3,38.3,72.1$ and $69.6 \%$ agreement, respectively $(p=$ $0.0013)$. Results for all practitioner/practice characteristics are presented in Table 3 Appendix online [15].

\section{Discussion}

The network provides an opportune setting in which to evaluate concordance between dental practitioners' reported

Table 2 Agreement on treatment recommendation listed in top three choices for management of dentin hypersensitivity

\begin{tabular}{llll}
\hline Treatment Recommended & $\begin{array}{l}\text { Product Listed in Top Three on Survey } \\
\mathrm{n}(\%)\end{array}$ & $\begin{array}{l}\text { Agreement Between Survey and Exam } \\
\%(95 \% \mathrm{Cl})\end{array}$ & $\begin{array}{l}\text { Kappa } \\
(95 \% \mathrm{Cl})\end{array}$ \\
\hline $\begin{array}{l}\text { Fluoride Products } \\
\text { Desensitizing OTC Potassium }\end{array}$ & $156(91.2 \%)$ & $72.5 \%(65.2,79.1)$ & $0.08(-0.06,0.22)$ \\
Nitrate Toothpaste & $150(87.7 \%)$ & $73.1 \%(65.8,79.6)$ & $0.26(0.12,0.41)$ \\
Restorative Treatments & $54(31.6 \%)$ & $70.8 \%(63.3,77.5)$ & $0.21(0.07,0.36)$ \\
Glutaraldehyde/HEMA Products & $41(24.0 \%)$ & $77.8 \%(70.8,83.8)$ & $0.19(0.04,0.34)$ \\
Bonding Agents & $34(19.9 \%)$ & $81.3 \%(74.6,86.8)$ & $0.29(0.11,0.47)$ \\
Advice & $26(15.2 \%)$ & $60.8 \%(53.1,68.2)$ & $0.00(-0.13,0.13)$ \\
Other & $16(9.4 \%)$ & $69.6 \%(62.1,76.4)$ & $0.22(0.09,0.34)$ \\
Oxalates & $8(4.7 \%)$ & $91.8 \%(86.6,95.5)$ & $0.18(-0.08,0.44)$ \\
Sealants & $8(4.7 \%)$ & $95.3 \%(91.0,98.0)$ & $0.18(-0.14,0.51)$ \\
No Treatment & $7(4.1 \%)$ & $90.6 \%(85.3,94.6)$ & $0.23(-0.02,0.48)$ \\
Lasers & $2(1.2 \%)$ & $100 \%(97.9,100)$ & $1.0(1.0,1.0)$ \\
\hline
\end{tabular}

$\mathrm{N}=171$

95\% confidence intervals in parentheses 
treatment preferences and methods and treatment choices as observed in an actual clinical setting. Analysis of concordance is necessary in order to establish the validity of questionnaire data to describe typical clinical practice. Data from the MDH study provides a context for the evaluation of this for a specific clinical scenario, that of $\mathrm{DH}$, and was chosen as the basis for the current study because the MDH study collected both questionnaire and clinical data and so provided the opportunity to evaluate concordance. All of the patients who were enrolled in the MDH study had been diagnosed with $\mathrm{DH}$, so neither incidence nor prevalence of $\mathrm{DH}$ is estimable from that study. These measures are not necessary to the evaluation of agreement between the two modes of collection of information.

Fluoride products and desensitizing OTC potassium nitrate toothpaste were the items selected by the most dentists as first-choice and as first-, second- or third-choice recommendations for management of DH. However, agreement between pre-study hypothetical questionnaire responses with observed rankings of items recommended during actual clinical examinations was modest for these items. Relatively high unadjusted agreement, often above $90 \%$, was observed for some items selected by only a small number of dentists. This seems to be largely the result of dentists who did not favor the use of these items on the questionnaire also not tending to use them in clinical examinations.

Guidelines for characterization of agreement based on ranges of values of Cohen's kappa statistic are arbitrary, but are often presented. A commonly-used set of such ranges [16], suggests that kappa greater than 0.75 indicates excellent agreement, 0.40 to 0.75 as fair to good, and below 0.40 as poor. Based on this, agreement on all items as ranked choices evaluated in this study was poor, with the exception of that for lasers. Only one dentist indicated lasers as first-choice, and two dentists indicated lasers as in the top three choices, and agreement between the survey responses and clinical recommendations was almost complete, at 99.4 and $100.0 \%$, respectively. The survey did not address the availability of lasers in the practices.

The practitioners' responses to the pre-study questionnaire are presumably based on their impressions of their typical practice. Characteristics of the patients who were enrolled in the clinical study might have differed from this expectation, and this could have affected agreement. In particular, practitioners who have multiple practice locations might consider different patient groups when completing the questionnaire, but clinical data were collected at only a single practice, so patient characteristics might differ from those of the aggregate.

It is not surprising that indication of a product/treatment as being in the top three would show higher agreement than that for first-choice. The top-three category is a larger target than the first-choice alone, and there are three chances for inclusion of a particular treatment recommendation. It is also possible that patients might have previously received a dentist's first-choice recommendation without success, so that the dentist recommends a second- or third-choice approach for this patient.

A high percentage agreement for products/recommendations that were indicated by only a few dentists primarily reflects good agreement for non-use of those items. Dentists who did not choose these items on the pre-study questionnaire also did not tend to recommend them in the patient examinations.

Formal comparisons among agreement estimates in different studies may not be possible because of differences in methodology across studies. Previous network studies have reported concordance between dentists' questionnaire responses and actual treatment practices regarding the choice of whether to repair or to replace dental restorations [3], between self-reported treatment planning thresholds and clinical choices [4], between stated treatment thresholds and clinical pre-treatment depth estimates [2] and between pre-operative and post-operative estimates of caries lesion depths [1]. Nonetheless, comparisons with other network studies may be of interest. Agreement for the two most-frequent recommendations in the current study were $63.7 \%$ for OTC potassium nitrate toothpaste and $63.2 \%$ for fluoride products.

Higher agreement levels might be expected for preand post-treatment clinical observations of the same clinical entity, such as the same caries lesion. For example, in one network study that quantified the agreement between pre- and post-intervention estimates of caries lesion depth, agreement of $88 \%$ was observed for lesions extending to the inner one-third of dentin and $54 \%$ for lesions limited to the outer one-half of enamel [1]. However, excellent agreement has also been found between stated treatment thresholds and pre-treatment estimates of caries lesion depth for lesions that were on the proximal surface (98\% agreement), but agreement for occlusal lesions was only $51 \%$ in the same study [2].

\section{Conclusions}

Agreement percentages between hypothetical, typical clinical scenarios (based on questionnaire data) and actual practice (based on clinical examination data) were generally high, but low values of Cohen's kappa indicated little agreement beyond levels that would be expected by chance. Based on this, survey data and hypothetical scenarios could supplement observations based on actual examinations in studies of $\mathrm{DH}$ treatment recommendations, but these should not take the place of data based on clinical observations. This analysis adds to the larger work of the network which has observed a wide range of levels of agreement between hypothetical and actual care, depending upon the specific diagnosis or treatment under consideration. 


\section{Appendix}

Table 3 Association of practitioner and practice characteristics with agreement on the practitioners' top three treatment recommendations

\begin{tabular}{|c|c|c|c|c|}
\hline Treatment Recommendation & Practitioner Characteristic & Categories & Agreement (\%) & $p$-value \\
\hline \multirow[t]{16}{*}{ Fluoride } & \multirow[t]{4}{*}{ Age Group } & $27-39$ & 69.7 & \multirow[t]{4}{*}{0.9212} \\
\hline & & $40-49$ & 70.6 & \\
\hline & & $50-59$ & 72.4 & \\
\hline & & $60+$ & 76.1 & \\
\hline & \multirow[t]{2}{*}{ Gender } & Male & 71.7 & \multirow[t]{2}{*}{0.7601} \\
\hline & & Female & 73.9 & \\
\hline & \multirow[t]{2}{*}{ Race } & White & 71.9 & \multirow[t]{2}{*}{0.7742} \\
\hline & & Other & 74.3 & \\
\hline & \multirow[t]{2}{*}{ Full Time/Part Time } & Full & 72.3 & \multirow[t]{2}{*}{0.9964} \\
\hline & & Part & 72.7 & \\
\hline & \multirow[t]{4}{*}{ Practice Location Type } & Inner city & 80.0 & \multirow[t]{4}{*}{0.9017} \\
\hline & & Urban (not inner city) & 70.2 & \\
\hline & & Suburban & 72.1 & \\
\hline & & Rural & 73.9 & \\
\hline & \multirow[t]{2}{*}{ Number of Locations } & 1 & 73.5 & \multirow[t]{2}{*}{0.6033} \\
\hline & & $2+$ & 68.2 & \\
\hline \multirow[t]{16}{*}{ OTC Potassium nitrate toothpaste } & \multirow[t]{4}{*}{ Age Group } & $27-39$ & 87.9 & \multirow[t]{4}{*}{0.1647} \\
\hline & & $40-49$ & 64.7 & \\
\hline & & $50-59$ & 70.7 & \\
\hline & & $60+$ & 71.7 & \\
\hline & \multirow[t]{2}{*}{ Gender } & Male & 74.5 & \multirow[t]{2}{*}{0.5905} \\
\hline & & Female & 70.8 & \\
\hline & \multirow[t]{2}{*}{ Race } & White & 72.6 & \multirow[t]{2}{*}{0.8408} \\
\hline & & Other & 74.3 & \\
\hline & \multirow[t]{2}{*}{ Full Time/Part Time } & Full & 72.3 & \multirow[t]{2}{*}{0.6240} \\
\hline & & Part & 77.3 & \\
\hline & \multirow[t]{4}{*}{ Practice Location Type } & Inner city & 86.7 & \multirow[t]{4}{*}{0.2274} \\
\hline & & Urban (not inner city) & 68.1 & \\
\hline & & Suburban & 76.7 & \\
\hline & & Rural & 60.9 & \\
\hline & \multirow[t]{2}{*}{ Number of Locations } & 1 & 76.2 & 0.0322 \\
\hline & & $2+$ & 54.6 & \\
\hline Glutaraldehyde / HEMA & Age Group & $27-39$ & 63.6 & 0.0805 \\
\hline & & $40-49$ & 73.5 & \\
\hline & & $50-59$ & 86.2 & \\
\hline & & $60+$ & 80.4 & \\
\hline & Gender & Male & 75.5 & 0.3543 \\
\hline & & Female & 81.5 & \\
\hline & Race & White & 80.0 & 0.1481 \\
\hline & & Other & 68.6 & \\
\hline & Full Time/Part Time & Full & 77.7 & 0.9640 \\
\hline & & Part & 77.3 & \\
\hline
\end{tabular}


Table 3 Association of practitioner and practice characteristics with agreement on the practitioners' top three treatment recommendations (Continued)

\begin{tabular}{|c|c|c|c|c|}
\hline Treatment Recommendation & Practitioner Characteristic & Categories & Agreement (\%) & $p$-value \\
\hline & Practice Location Type & Inner city & 60.0 & 0.1722 \\
\hline & & Urban (not inner city) & 72.3 & \\
\hline & & Suburban & 82.6 & \\
\hline & & Rural & 82.6 & \\
\hline & Number of Locations & 1 & 78.2 & 0.9192 \\
\hline & & $2+$ & 77.3 & \\
\hline \multirow[t]{17}{*}{ Bonding Agents } & Age Group & $27-39$ & 81.8 & 0.6491 \\
\hline & & $40-49$ & 76.5 & \\
\hline & & $50-59$ & 79.3 & \\
\hline & & $60+$ & 87.0 & \\
\hline & Gender & Male & 79.3 & 0.3821 \\
\hline & & Female & 84.6 & \\
\hline & Race & & & \\
\hline & & White & 80.0 & 0.4409 \\
\hline & & Other & 85.7 & \\
\hline & Full Time/Part Time & Full & 80.4 & 0.5047 \\
\hline & & Part & 86.4 & \\
\hline & Practice Location Type & Inner city & 93.3 & 0.0776 \\
\hline & & Urban (not inner city) & 70.2 & \\
\hline & & Suburban & 82.6 & \\
\hline & & Rural & 91.3 & \\
\hline & Number of Locations & 1 & 81.6 & 0.9833 \\
\hline & & $2+$ & 81.8 & \\
\hline \multirow[t]{16}{*}{ Sealants } & Age Group & $27-39$ & 21.2 & 0.3074 \\
\hline & & $40-49$ & 35.3 & \\
\hline & & $50-59$ & 36.2 & \\
\hline & & $60+$ & 41.3 & \\
\hline & Gender & Male & 34.0 & 0.8494 \\
\hline & & Female & 35.4 & \\
\hline & Race & White & 33.3 & 0.4603 \\
\hline & & Other & 40.0 & \\
\hline & Full Time/Part Time & Full & 33.8 & 0.5124 \\
\hline & & Part & 40.9 & \\
\hline & Practice Location Type & Inner city & 40.0 & 0.4393 \\
\hline & & Urban (not inner city) & 34.0 & \\
\hline & & Suburban & 30.2 & \\
\hline & & Rural & 47.8 & \\
\hline & Number of Locations & 1 & 33.3 & 0.4852 \\
\hline & & $2+$ & 40.9 & \\
\hline \multirow[t]{4}{*}{ Restorative Treatments } & Age Group & $27-39$ & 75.8 & 0.6353 \\
\hline & & $40-49$ & 15.2 & \\
\hline & & $50-59$ & 69.0 & \\
\hline & & $60+$ & 65.2 & \\
\hline
\end{tabular}


Table 3 Association of practitioner and practice characteristics with agreement on the practitioners' top three treatment recommendations (Continued)

\begin{tabular}{|c|c|c|c|c|}
\hline Treatment Recommendation & Practitioner Characteristic & Categories & Agreement (\%) & $\overline{p \text {-value }}$ \\
\hline & \multirow[t]{2}{*}{ Gender } & Male & 69.8 & \multirow[t]{2}{*}{0.7276} \\
\hline & & Female & 72.3 & \\
\hline & \multirow[t]{2}{*}{ Race } & White & 69.6 & \multirow[t]{2}{*}{0.5901} \\
\hline & & Other & 74.3 & \\
\hline & \multirow[t]{2}{*}{ Full Time/Part Time } & Full & 68.9 & \multirow[t]{2}{*}{0.0919} \\
\hline & & Part & 86.4 & \\
\hline & \multirow[t]{4}{*}{ Practice Location Type } & Inner city & 73.3 & \multirow[t]{4}{*}{0.7303} \\
\hline & & Urban (not inner city) & 76.6 & \\
\hline & & Suburban & 67.4 & \\
\hline & & Rural & 69.6 & \\
\hline & \multirow[t]{2}{*}{ Number of Locations } & 1 & 68.7 & \multirow[t]{2}{*}{0.2089} \\
\hline & & $2+$ & 81.8 & \\
\hline \multirow[t]{16}{*}{ Oxalates } & \multirow[t]{4}{*}{ Age Group } & $27-39$ & 90.9 & \multirow[t]{4}{*}{0.9588} \\
\hline & & $40-49$ & 94.1 & \\
\hline & & $50-59$ & 91.4 & \\
\hline & & $60+$ & 91.3 & \\
\hline & \multirow[t]{2}{*}{ Gender } & Male & 92.5 & \multirow[t]{2}{*}{0.6967} \\
\hline & & Female & 90.8 & \\
\hline & \multirow[t]{2}{*}{ Race } & White & 90.4 & \multirow[t]{2}{*}{0.1940} \\
\hline & & Other & 97.1 & \\
\hline & \multirow[t]{2}{*}{ Full Time/Part Time } & Full & 93.2 & \multirow[t]{2}{*}{0.0689} \\
\hline & & Part & 81.8 & \\
\hline & \multirow[t]{4}{*}{ Practice Location Type } & Inner city & 100.0 & \multirow[t]{4}{*}{0.2253} \\
\hline & & Urban (not inner city) & 89.4 & \\
\hline & & Suburban & 89.5 & \\
\hline & & Rural & 100.0 & \\
\hline & \multirow[t]{2}{*}{ Number of Locations } & 1 & 91.8 & \multirow[t]{2}{*}{0.8830} \\
\hline & & $2+$ & 90.9 & \\
\hline \multirow[t]{15}{*}{ No Treatment } & \multirow[t]{4}{*}{ Age Group } & $27-39$ & 90.9 & 0.3070 \\
\hline & & $40-49$ & 82.4 & \\
\hline & & $50-59$ & 93.1 & \\
\hline & & $60+$ & 93.5 & \\
\hline & Gender & Male & 89.6 & 0.5584 \\
\hline & & Female & 92.3 & \\
\hline & Race & White & 90.4 & 0.8485 \\
\hline & & Other & 91.4 & \\
\hline & Full Time/Part Time & Full & 90.5 & 0.9559 \\
\hline & & Part & 90.9 & \\
\hline & Practice Location Type & Inner city & 80.0 & 0.4435 \\
\hline & & Urban (not inner city) & 89.4 & \\
\hline & & Suburban & 93.0 & \\
\hline & & Rural & 91.3 & \\
\hline & Number of Locations & 1 & 91.8 & 0.1344 \\
\hline
\end{tabular}


Table 3 Association of practitioner and practice characteristics with agreement on the practitioners' top three treatment recommendations (Continued)

\begin{tabular}{|c|c|c|c|c|}
\hline Treatment Recommendation & Practitioner Characteristic & Categories & Agreement (\%) & $p$-value \\
\hline & & $2+$ & 81.8 & \\
\hline \multirow[t]{16}{*}{ Advice } & Age Group & $27-39$ & 72.7 & 0.3679 \\
\hline & & $40-49$ & 55.9 & \\
\hline & & $50-59$ & 62.1 & \\
\hline & & $60+$ & 54.4 & \\
\hline & Gender & Male & 65.1 & 0.1436 \\
\hline & & Female & 53.9 & \\
\hline & Race & White & 60.7 & 0.9363 \\
\hline & & Other & 60.0 & \\
\hline & Full Time/Part Time & Full & 60.8 & 0.8776 \\
\hline & & Part & 59.1 & \\
\hline & Practice Location Type & Inner city & 53.3 & 0.0013 \\
\hline & & Urban (not inner city) & 38.3 & \\
\hline & & Suburban & 72.1 & \\
\hline & & Rural & 69.6 & \\
\hline & Number of Locations & 1 & 61.2 & 0.8483 \\
\hline & & $2+$ & 59.1 & \\
\hline \multirow[t]{16}{*}{ Other } & Age Group & $27-39$ & 69.7 & 0.3813 \\
\hline & & $40-49$ & 64.7 & \\
\hline & & $50-59$ & 77.6 & \\
\hline & & $60+$ & 63.0 & \\
\hline & Gender & Male & 68.9 & 0.7930 \\
\hline & & Female & 70.8 & \\
\hline & Race & White & 68.2 & 0.4825 \\
\hline & & Other & 74.3 & \\
\hline & Full Time/Part Time & Full & 70.3 & 0.5286 \\
\hline & & Part & 63.6 & \\
\hline & Practice Location Type & Inner city & 60.0 & 0.5872 \\
\hline & & Urban (not inner city) & 76.6 & \\
\hline & & Suburban & 67.4 & \\
\hline & & Rural & 69.6 & \\
\hline & Number of Locations & 1 & 67.4 & 0.0699 \\
\hline & & $2+$ & 86.4 & \\
\hline
\end{tabular}

\section{Additional files}

Additional file 1: Sensitive Teeth Study Online Practitioner

Questionnaire. Pre-Study Questionnaire: Information on practitioners' diagnosis and treatment modalities used when seeing patients presenting with a dentin hypersensitivity complaint. (PDF $226 \mathrm{~kb}$ )

Additional file 2: Sensitive Teeth Study Baseline Exam. Patient Baseline Examination Form: Information on number and location of sensitive teeth and recommended treatments. (PDF $221 \mathrm{~kb}$ )

Additional file 3: STROBE Checklist. Completed STROBE Checklist (DOC $79 \mathrm{~kb}$ )
Abbreviations

Cl: Confidence interval; DH: Dentin hypersensitivity; MDH: Management of dentin hypersensitivity

\section{Acknowledgements}

We are very grateful to the regional coordinators who were involved in both the questionnaire and clinical study phases (Midwest Region: Kimberly Johnson, RDH, MDH; Western Region: Stephanie Hodge, MA; Northeast Region: Rita Cacciato, RDH, MS; South Atlantic Region: Deborah McEdward, RDH, BS, CCRP; South Central Region: Claudia Carcelén, MPH, Shermetria Massengale, MPH, CHES, Ellen Sowell, BA; Southwest Region: Meredith Buchberg, MPH, Colleen Steward MPH; Western Region: Camille Baltuck, 
$\mathrm{RDH})$. Opinions and assertions contained herein are those of the authors and are not to be construed as necessarily representing the views of the respective organizations or the National Institutes of Health. National Dental PBRN Collaborative Group.

The National Dental PBRN Collaborative Group includes practitioner, faculty, and staff investigators who contributed to this activity. A list is available at http://nationaldentalpbrn.org/collaborative-group.php Concordance between practitioner questionnaire responses and observed clinical treatment recommendations for treatment of dentin hypersensitivity: findings from the National Dental Practice-Based Research Network.

\section{Funding}

This work was supported by NIH grant U19-DE-22516. An Internet site devoted to details about the nation's network is located at http://NationalDentalPBRN. org. The funding body did not participate in the study design, data collection, analysis and interpretation of the study data or in writing the manuscript.

\section{Availability of data and materials}

Data collection forms for this study are publicly available on the National Dental PBRN website http://nationaldentalpbrn.org/study-results/ management-of-dentin-hypersensitivity.php. The National Dental PBRN makes data from its studies publicly available in fully de-identified form after the grant's funding period has ended.

\section{Authors' contributions}

MSL participated in study design, conducted the statistical analysis, conducted the literature review and drafted and edited the manuscript. DKK participated in study design and survey design, served as study PI and reviewed and edited the manuscript. DBR provided critical review and editing of the manuscript. JLF provided critical review and editing of the manuscript. MWH provided critical review and editing of the manuscript. CM provided critical review and editing of the manuscript. SC provided critical review and editing of the manuscript. GHG participated in survey design, provided critical review and editing of the manuscript, and serves as PI for the National Dental Practice-Based Research Network. All authors read and approved the final manuscript.

\section{Ethics approval and consent to participate}

The study was approved by the University of Rochester Research Subject Review Board (approval number RSRB 00053321) and also by the IRBs of the remaining five study sites, as follows: The University of Florida Health Center Institutional Review Board, The UT Health Science Center San Antonio Institutional Review Board, Kaiser Permanente Northwest Institutional Review Board, HealthPartners Institute for Education \& Research, and The University of Alabama at Birmingham Office of the Institutional Review Board for Human Use.

The informed consent of all human subjects who participated in this investigation was obtained after the nature of the procedures had been explained fully. As per regional IRB requirements written informed consents were used in the Midwest, South Atlantic and Northeast regions of the network and verbal informed consents were used in South Central, Western and Southwestern regions of the network. The use of verbal informed consent was approved by The University of Alabama at Birmingham Office of the Institutional Review Board for Human Use for the South Central Region; by the UT Health Science Center San Antonio Institutional Review Board for the Southwest Region; and by Kaiser Permanente Northwest Institutional Review Board for the Western Region.

\section{Consent for publication}

Not Applicable.

\section{Competing interests}

The authors declare that they have no competing interests.

\section{Publisher's Note}

Springer Nature remains neutral with regard to jurisdictional claims in published maps and institutional affiliations.

\section{Author details}

'Department of Clinical and Community Sciences, University of Alabama at Birmingham, 1919 7th Avenue South, Birmingham, AL 35294-0007, USA.
2Eastman Institute for Oral Health, University of Rochester, 625 Elmwood Ave, Rochester, NY 14620, USA. ${ }^{3}$ Health Partners Institute for Education and Research, 8170 33rd Avenue South, Mail Stop 21111R, PO Box 1524, Bloomington, MN 55440-1524, USA. ${ }^{4}$ Kaiser Permanente Center for Health Research, $3800 \mathrm{~N}$ Interstate Avenue, Portland, OR 97227, USA. ${ }^{5}$ Department of Oral \& Maxillofacial Surgery, College of Dentistry, University of Florida, Gainesville, FL 32610-0416, USA. ${ }^{6}$ Private Practice of General Dentistry, 66 Maple Ave, Morristown, NJ 07960, USA.

Received: 3 May 2018 Accepted: 26 April 2019

Published online: 14 June 2019

\section{References}

1. Nascimento MM, Bader JD, Qvist V, Litaker MS, Williams OD, Rindal DB, Fellows JL, Gilbert GH, Gordan W, For the DPBRN collaborative group. Concordance between pre-operative and post-operative assessments of primary caries lesion depth: results from the dental PBRN. Oper Dent. 2010; 35(4):389-96.

2. Rindal DB, Gordan W, Fellows JL, Spurlock NL, Bauer MR, Litaker MS, Gilbert $\mathrm{GH}$, for the dental PBRN collaborative group. Differences between reported and actual restored caries lesion depths: results from the dental PBRN. J Dent. 2012:40(3):248-54.

3. Heaven TJ, Gordan W, Litaker MS, Fellows JL, Rindal DB, Gilbert GH, For the National Dental PBRN collaborative group. Concordance between responses to questionnaire scenarios and actual treatment to repair or replace dental restorations in the National Dental PBRN. J Dent. 2015;43(11):1379-84.

4. Heaven TJ, Gordan W, Litaker MS, Fellows JL, Rindal DB, Firestone AR, Gilbert GH, For the National Dental PBRN collaborative group. Agreement among dentists' restorative treatment planning thresholds for primary occlusal caries, primay proximal caries and existing restorations: findings from the National Dental Practice-Based Research Network. J Dent. 2013; 41(8):718-25.

5. Norton WE, Funkhouser E, Makhija SK, Gordan W, Bader JD, Rindal DB, Pihlstrom DJ, Hilton TJ, Frantsve-Hawley J, Gilbert GH, The National Dental Practice-Based Research Network Collaborative Group. Concordance between clinical practice and published evidence. JADA. 2014;145(1):22-31.

6. Chiang HK, Best AM, Sarrett DC. Concordance between clinical practice and published evidence: findings from Virginia Commonwealth University School of Dentistry. J Evid Based Dent Pract. 2017;17(3):169-76.

7. Galgut PN, Calabrese N. A comparison of diagnostic screening data derived from general dental practitioners and periodontists used for initial treatment planning in periodontitis patients. J Int Acad Periodontol. 2007; 9(4):106-11.

8. Kopycka-Kedzierawski DT, Meyerowitz C, Litaker MS, Chonowski S, Heft MW, Gordan W, Yardic RL, Madden TE, Reyes SC, Gilbert GH, National Dental PBRN collaborative group. Management of dentin hypersensitivity by National Dental Practice-Based Research Network practitioners: results from a questionnaire administered prior to initiation of a clinical study on this topic. BMC Oral Health. 2017;17:41.

9. Kopycka-Kedzierawski DT, Meyerowitz C, Litaker MS, Heft MW, Tasgaonkar N, Day MR, Porter-Williams A, Gordan W, Yardic RL, Lawhorn TM, Gilbert GH, National Dental PBRN collaborative group. Management of dentin hypersensitivity by practitioners in the National Dental Practice-Based Research Network. J Am Dent Assoc. 2017;148(10):728-36.

10. Gilbert GH, Williams OD, Korelitz JJ, Fellows JL, Gordan W, Makhija SK, Meyerowitz C, Oates TW, Rindal DB, Benjamin PL, Foy PL, National Dental PBRN collaborative group. Purpose, structure and function of the United States National Dental Practice-Based Research network. J Dent. 2013;41: 1051-9.

11. The National Dental Practice-Based Research Network: The Nation's Network. http://www.nationaldentalpbrn.org/. Accessed 12 Apr 2018.

12. The National Dental Practice-Based Research Network: The Nation's Network. Enroll Now. http://nationaldentalpbrn.org/enrollment.php. Accessed 20 Apr 2018.

13. The National Dental Practice-Based Research Network: the Nation's network. Management of Dentin Hypersensitivity. http://www.nationaldentalpbrn. org/study-results/management-of-dentin-hypersensitivity.php. Accessed 12 Apr 2018.

14. The National Dental Practice-Based Research Network. Sensitive Teeth Study, Baseline Exam. http://www.nationaldentalpbrn.org/tyfoon/site/ 
fckeditor/MDH-Baseline-Exam-Form-2015-02-12-V2_0.pdf. Accessed 11 Apr 2018.

15. The National Dental Practice-Based Research Network: The Nation's Network. Management of Dentin Hypersensitivity. Appendix Table 3. http:// nationaldentalpbrn.org/tyfoon/site/fckeditor/Appendix\%20Table\%203_SC_1. pdf. Accessed 12 Apr 2018.

16. Fleiss JL. Statistical methods for rates and proportions. 2nd ed. New York: Wiley; 1981. ISBN 0-471-26370-2

Ready to submit your research? Choose BMC and benefit from:

- fast, convenient online submission

- thorough peer review by experienced researchers in your field

- rapid publication on acceptance

- support for research data, including large and complex data types

- gold Open Access which fosters wider collaboration and increased citations

- maximum visibility for your research: over $100 \mathrm{M}$ website views per year

At $\mathrm{BMC}$, research is always in progress.

Learn more biomedcentral.com/submissions 